\title{
The problem of choice of optimal technological decisions on harvester control
}

\author{
Valery P. Dimitrov ${ }^{1, *}$, Lyudmila V. Borisova ${ }^{2}$, Inna N. Nurutdinova ${ }^{3}$, Viktor I. Pakhomov ${ }^{4}$, \\ and V.P. Maksimov ${ }^{5}$ \\ ${ }^{1}$ Don State Technical University, Quality Management Department, 344000 Rostov-on-Don, Russia \\ ${ }^{2}$ Don State Technical University, Management and Business Technology Department, 344000 \\ Rostov-on-Don, Russia \\ ${ }^{3}$ Don State Technical University, Applied Mathematics Department, 344000 Rostov-on-Don, Russia \\ ${ }^{4}$ State Scientific Establishment "Agriculture research center "Donskoy", North Caucasus Institute of \\ Mechanization and Electrification of Agriculture, 347740 Zernograd, Russia \\ ${ }^{5}$ Novocherkassk Engineering Institute Reclamation Name A. K. Kortunova, Don State Agrarian \\ University, 346428 Novocherkassk, Russia
}

\begin{abstract}
The paper considers the problem of determining optimal technological decisions on a harvester control which includes the choice of the harvester adjustable parameters at presetting and also their updating in the process of operation. To solve this problem, an information system of decision making support based on fuzzy expert knowledge is used. The expedience of this approach is stipulated by the data fuzziness about the factors of the environment in which the harvester is operating and also by complex and system of uncertain interrelations among external factors, adjustable parameters and harvesting quality indices. For the case of harvesting grain crops an expert knowledge base has been made which makes it possible to formalize empirical knowledge about the dependencies of the harvester adjustable parameters on the environment factors such as crop yield, stand of grain humidity, stand of grain dockage rough straw. The most essential adjustable parameters have been considered: speed of the harvester motion, rotational speed of a threshing drum and rotor speed of a separator fan. Fuzzy logic inference has been performed with the help of Fuzzy Logic Toolbox application package (Matlab). The examples of technological decisions of the harvester preliminary adjustment at different environmental conditions have been presented, accurate values of the adjustable parameters were calculated by the «barycentre» method.
\end{abstract}

\footnotetext{
${ }^{*}$ Corresponding author: dimitrovvalery@yandex.ru
} 


\section{Introduction}

It is common knowledge, that efficiency of using a grain combine harvester, and, consequently, resulting character of harvesting depend on successful solution of the problem of technological process control being performed by the harvester [1]. Search for optimal solutions is defined by a specific character of the object domain under consideration. External factors, harvesting quality indices, parameters of technical condition and adjustable parameters are characterized by variability, uncertainty, and, predominantly, are presented by quality indices (dry stand, high dockage and so on).

For the effective carrying out of harvesting, it is required an adequate mathematical description of the decision making process on technological setting which is defined by the used model of the object domain knowledge. In a number of papers [2-4] correlationregressive models were used. In these models, relations among external factors, adjustable parameters, and quality indices were described by empirical formulae obtained as a result of the empirical data processing. Accuracy of solutions on the basis of such models depends on reliability of input factors values. Furthermore, in this case it is necessary to take into account correlation of factors, experimental determination of which is often practically an insolvable problem. As a result, correlation-regressive models are awkward, they do not always adequately reflect the facts, and their use in real time under practical conditions is difficult. The authors of the mentioned papers also pay attention to this, and they recommend us to use these models as estimating only.

To solve the problems of optimal technological adjustment the intelligent automated systems on the basis of fuzzy control [5] can be used, they accumulate all kinds of knowledge including expert and heuristic knowledge, rely on the gained experience of operation under different conditions. Similar systems are used in agricultural production, mainly in relation to image analysis, weather conditions, processing or sorting the products, weeds identification, estimation of harvest etc., for example, [6-8]. In the papers $[9,10]$ the questions of automatic choice of some harvester adjustable parameters on the basis of production rules were considered.

The previous investigations [11-12] make it clear that the given object domain is complex and at present is not formalized enough. Therefore, the necessity of solving the problems of the harvester technological adjustment stipulates the demand for searching new methods of solution.

\section{Problem definition}

Formalization complexity of the object domain "Harvester technological adjustment" is stipulated by uncertainty of the initial data and also by absence of formal description of interrelations among adjustable parameters and external factors. So, the problems of presetting and updating of technological adjustments are strongly marked problems of decision making in fuzzy conditions, and this determines the necessity of applying mathematical apparatus of the theory of fuzzy sets [13].

Let us introduce the "technological solution" concept for the problem of presetting. Technological solution is a rational (at the best case - optimal) set of values of the adjustable parameters and the parameters of the harvester technical condition which provides reasonable values of the harvesting quality indices. Let us denote $\operatorname{Tr}$ as a set of technological solutions.

Suppose $D n$ is a set of initial data. In the general case, initial data can include parameters of technological solutions. Initial data will be sets of values of external factors, 
i.e. climatic factors, stand of grain parameters and parameters of the machine technical condition, harvesting quality indices.

Let $S t$ is a set of situations. A situation refers to a set of condition descriptions which define interaction of the objects under consideration (environmental factor - reaping part, environmental factor - separator etc.). The situations are represented as heuristic knowledge, for example, if shattering of grain is extensive, then rotational speed of the threshing drum should be reduced.

Then the solution process of the problem on the harvester presetting is mapping:

$$
F: S t \times D n \rightarrow T r,
$$

where: is a sign of the function content expansion, $\times$ is a sign of Cartesian product, $\rightarrow$ is an implication sign (logical implication).

Therefore, the processes of harvester tools presetting and technological adjustments updating can be described by means of state space, the elements of which by structure and content depend on characteristic features of this or that harvester tool.

To solve the problem of presetting for any initial data it is necessary to have description of all states that can be generated automatically as a result of application of special rules. These rules are the knowledge base of the information system on the harvester control.

The data characterizing the problems of presetting and updating of technological adjustments can be decomposed into three categories:

1. Information describing technological solutions (a set of values of the adjustable parameters for setting or a set of values of adjustable parameters for updating).

2. Information describing initial data for each problem (values of environmental factors and the parameters of the harvester technical condition, and also the values of the operation quality indices and the values of adjustable parameters).

3. Information describing a situation (description of dependencies of external factors influence on the values of the adjustable parameters and dependencies of adjustable parameters influence on the operation quality indices).

Information referring to item 1 is considered in [14]. The questions of presenting expert information on the values of environmental factors and the parameters of technological setting (item 2) in the form of the corresponding linguistic variables are presented in [15-17]. The present paper considers the questions referring to item 3, i.e. questions of decision making on the parameters of technological adjustment.

\section{Problem solution}

When describing the process of decision making, we will proceed from the fact that it is characterized by several input and one output parameters. When there are several output parameters, then the process can be presented in the form of several parallel processes with one output parameter. Information on the strategies of decision making in typical situations obtained from an expert is described by the system of statements which establish relations among input factors and adjustable parameters. The statements have the form of rules of the kind: IF "Condition_1, THEN "Conclusion_1". In this way the formalization of empirical knowledge in the object domain under consideration takes place. This finite set of rules of fuzzy products, correlated with respect to the linguistic variables used in them, forms a base of fuzzy knowledge and is in the basis of fuzzy logic inference. For the purpose of implementation of the fuzzy logic inference, it is convenient to use Fuzzy Logic Toolbox application package (Matlab).

To solve the problem of technological adjustment and updating of the parameters there was created a base of product rules establishing relations among external factors and the 
parameters of technological setting. The knowledge base is structured in accordance with the kind of crop being harvested. In the following we will consider the harvesting of grain crops in the problem of presetting. In this case, significant external factors are crop yield (CY, q/ha), stand of grain humidity (SGH, \%), stand of grain dockage (SGD, \%) and rough straw (RS, \%). The corresponding linguistic variables are represented by 2 - and 3 -term models [17], and for construction of the membership functions we used standard functions of triangle and trapezoidal forms. All possible collections of external factors in different levels represent vectors $D n x=\{\mathrm{CY}, \mathrm{SGH}, \mathrm{SGD}, \mathrm{RS}\}$, forming the set of initial data $D n$.

With reference to output parameters, several main parameters were chosen for the purpose of study: speed of harvester $(\mathrm{SH}, \mathrm{km} / \mathrm{h})$, rotational speed of threshing drum (RSTD, rev/min), rotor speed of separator fan (RSSF, rev/min). Their linguistic description and membership functions are presented in [15]. Therefore, a set of technological solutions $\operatorname{Tr}$ are presented by the vectors $\operatorname{Tr} x=\{\mathrm{SH}, \mathrm{RSTD}, \mathrm{RSSF}\}$. We note, that the dimension of the vectors Dnx and Trx is arbitrary. The dimension of the vector Trx is stipulated by design features of the technical system being considered.

The process of decision making is presented as a system of parallel processes with one output parameter. For each output the production rules were formulated, they form a set St. We give 2 rules from each unit, each unit containing 36 production rules, for the case of wheat harvesting with the yield of crops approximately $50 \mathrm{q} / \mathrm{ha}$.

1. If $<$ (crop yield is less than 50) and (rough straw is low) and (dockage is low) and (stand of grain humidity is dry) $>$ then (speed of harvester is very high $>$

2. If $<$ (crop yield is less than 50) and (rough straw is low) and (dockage is low) and (stand of grain humidity is normal $)>$ then $<$ speed of harvester is high $>$

1. If $<$ (crop yield is less than 50) and (rough straw is low) and (dockage is low) and (stand of grain humidity is dry) $>$ then $<$ rotational speed of threshing drum is very low $>$

2. If $<$ (crop yield is less than 50) and (rough straw is low) and (dockage is low) and (stand of grain humidity is normal) $>$ then <rotational speed of threshing drum is less than nominal>

1 If $<$ (crop yield is less than 50) and (rough straw is low) and (dockage is low) and (stand of grain humidity is dry) $>$ then $<$ rotor speed of separator fan is very low)

2 If $<$ (crop yield is less than 50) and (rough straw is low) and (dockage is low) and (stand of grain humidity is normal) $>$ then $<$ rotor speed of separator fan is lower than nominal $>$

Analysis of the response surfaces, constructed in Fuzzy Logic Toolbox, has shown that the corresponding them systems of rules are consistent. Fig. 1 shows examples of the surfaces.

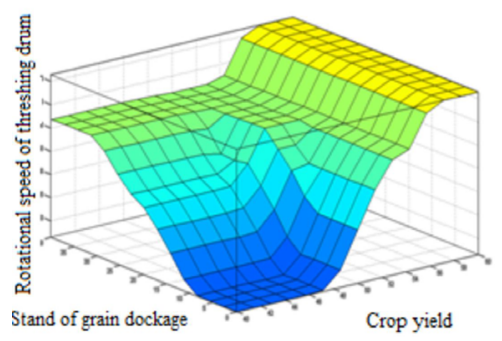

a)

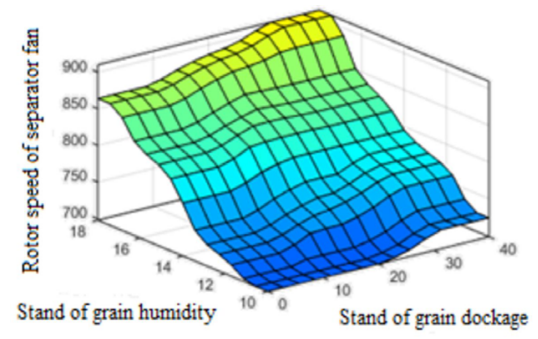

b)

Fig. 1. Response surfaces of a) rotational speed of the threshing drum vs stand of grain dockage and crop yield; b) rotor speed of the separator fan vs stand of grain humidity and stand of grain dockage. 
At the stage of defuzzification accurate values of the output linguistic variables are calculated. To perform numerical calculations a barycentre method was applied [18] which was implemented in Fuzzy Logic Toolbox. When assigning values of the initial factors Dnx and applying fuzzy logic inference on the basis of rules from the set $S t$ (1) we obtain accurate values of technical solutions $\operatorname{Tr} x$ of the parameters of the harvester technological adjustment. Table 1 presents the results for several combinations of the initial factors.

Table 1. Results of calculations of technical solutions

\begin{tabular}{|c|c|}
\hline Dnx $=\{$ CY, SGH, SGD, RS $\}$ & $\operatorname{Tr} \boldsymbol{x}=\{$ SH; RSTD; RSSF $\}$ \\
\hline$\{46,14,10,50\}$ & $\{3,3 ; 758 ; 749\}$ \\
\hline$\{46,16,10,50\}$ & $\{3,15 ; 805 ; 802\}$ \\
\hline$\{50,14,10,50\}$ & $\{3,2 ; 780 ; 770\}$ \\
\hline$\{50,16,10,50\}$ & $\{3,09 ; 825 ; 820\}$ \\
\hline
\end{tabular}

\section{Conclusion}

Knowledge base and the inference mechanism for the problems of presetting and updating technological parameters, created on the basis of the fuzzy model of the harvester operation in the field, form the basis of the intelligent information system (expert system). Practical implementation of the obtained results is the development of software applications for automated solution of the problem. The use of expert systems for technological adjustment in the field makes it possible to reduce time for operational downtime and minimize losses of yield, and this is verified by the results of using the prototype of the "Artificial expert" software system. The time taken for presetting and updating of technological adjustments decreases by a factor of $2-5$ times compared to the traditional methods, and the harvester productivity per shift increases by $10-12 \%$.

\section{References}

1. A. G. Rybalko, Some features of harvesting high-yield crops (Agropromizdat, Moscow, 1988)

2. S. N. Yerokhin, A. S. Reshetov, Mechanization and Electrification of Agriculture, 6, 18 (2003)

3. L. M. Litvin, E. V. Zhalkin, Ye. F. Vetrov, Machinery in Agriculture, 5, 41 (1989)

4. Yu. A. Tsarev, A. V. Kharkovskiy, Tractors and Agricultural Machinery, 1, 37 (2005)

5. L. Borisova, V. Dimitrov, I. Nurutdinova, Advances of Intelligent Systems and Computing, 680, 96 (2018)

6. H. Zareiforoush, S. Minaei, M. R. Alizadeh, A. Banakar A, B. H. Samani, Computers and Electronics in Agriculture, 124, 14 (2016)

7. M. Sujaritha, S. Annadurai, J. Satheeshkumar, S. Kowshik, L. Mahesha, Computers and Electronics in Agriculture, 134, 160 (2017)

8. J.T. Walls III, P. Caciagli, J.F. Tooker, J.M. Russo, E.G. Rajotte, and C. Rosa, Computers and Electronics in Agriculture, 127, 775 (2016)

9. M. Omid, M. Lashgar, H. Mobli, R. Alimardani, S. Mohtasebi and R. Hesamifard, Expert Systems with Applications, 37, 7080 (2010). 
10. G. Craessaert, J. de Baerdemaeker, B. Missotten and O. Saeys, Biosystems Engineering, 106, 103 (2010)

11. L.V. Borisova, I.N. Nurutdinova and V.P. Dimitrov, Vestnik of Don State Technical University, 15, 2(81), 100 (2015)

12. L. V. Borisova, V. P. Dimitrov, Mordovia University Bulletin, 27, 2, 178 (2017)

13. L. A. Zadeh, An Introduction to Fuzzy Logic Applications in Intelligent Systems, (Springer Science+Business Media, New York, 1992)

14. V. P. Dimitrov, L. V. Borisova, Formalization of fuzzy expert knowledge in the linguistic description of technical systems (DSTU, Rostov-on-Don, 2011)

15. V. Dimitrov, L. Borisova, I. Nurutdinova, MATEC Web Conf, 132, 04009 (2017)

16. L. Borisova, V. Dimitrov, I. Nurutdinova, Proceedings of IEEE East-West Design \& Test Symposium (EWDTS'2017), 319 (2017)

17. V. P. Dimitrov, L. V. Borisova, A. K. Tugengold, I. N. Nurutdinova, Mordovia University Bulletin, 28, 2, 239 (2018)

18. K. Asai, D. Vatada, S. Sugeno, Applied fuzzy systems (Mir , Moscow, 1993) 